OPEN ACCESS

International Journal of

Environmental Research and

Public Health

ISSN 1660-4601

www.mdpi.com/journal/ijerph

Article

\title{
Residents' Preferences for Household Kitchen Waste Source Separation Services in Beijing: A Choice Experiment Approach
}

Yalin Yuan ${ }^{1}$ and Mitsuyasu Yabe ${ }^{2, *}$

1 Laboratory of Environmental Economics, Graduate School of Bio-resources and Bio-environmental Science, Kyushu University, Fukuoka 812-8581, Japan; E-Mail: yalin-yuan@agr.kyushu-u.ac.jp

2 Laboratory of Environmental Economics, Department of Agricultural and Resource Economics, Faculty of Agriculture, Kyushu University, Fukuoka 812-8581, Japan

* Author to whom correspondence should be addressed; E-Mail: yabe@agr.kyushu-u.ac.jp; Tel./Fax: +81-92-642-2958.

Academic Editor: Oladele A. Ogunseitan

Received: 8 October 2014 / Accepted: 17 December 2014 / Published: 23 December 2014

\begin{abstract}
A source separation program for household kitchen waste has been in place in Beijing since 2010. However, the participation rate of residents is far from satisfactory. This study was carried out to identify residents' preferences based on an improved management strategy for household kitchen waste source separation. We determine the preferences of residents in an ad hoc sample, according to their age level, for source separation services and their marginal willingness to accept compensation for the service attributes. We used a multinomial logit model to analyze the data, collected from 394 residents in Haidian and Dongcheng districts of Beijing City through a choice experiment. The results show there are differences of preferences on the services attributes between young, middle, and old age residents. Low compensation is not a major factor to promote young and middle age residents accept the proposed separation services. However, on average, most of them prefer services with frequent, evening, plastic bag attributes and without instructor. This study indicates that there is a potential for local government to improve the current separation services accordingly.
\end{abstract}

Keywords: waste recycling; waste separation; household waste; multinomial logit model; China 


\section{Introduction}

Rapid population growth, urbanization, industrialization, and economic development have resulted in the generation of an enormous volume of solid waste in residential areas throughout the world, particularly in the rapidly growing cities of the developing countries. Separation of waste at the source is admittedly better than the recovery of materials from mixed wastes [1-4], because it produces cleaner, higher-quality materials as well as reduces the cost of disposal in the long run.

The metropolis of Beijing, in China, covers an area of approximately $1400 \mathrm{~km}^{2}$ and has a population of more than 20 million, approximately $86 \%$ of whom live in the urban area. The total municipal solid waste (MSW) transported in 2009 was 6.56 million tons, of which organic waste comprised over $60 \%$ [5]. However, only 4\% of total MSW was composted [6]. In 2010, the local government set targets to compost $30 \%$ of the MSW by the end of 2015. Meanwhile, the local government has been undertaking source separation campaigns since 2010.

\subsection{Program Progress}

Every year hundreds of communities are selected from all over Beijing as pilot communities, and households in these communities are encouraged to separate their kitchen waste from recyclable and other waste. By the end of 2012, this program covered 2412 communities - more than half of all the communities in Beijing. In order to achieve the cooperation of residents and encourage them to conduct source separation, local authorities have made great efforts, such as providing free household kitchen waste containers (half year's biodegradable plastic bags — one bag per day, and barrels) and hiring separation instructors to guide and help households correctly separate kitchen waste. Besides, they can deliver their waste into community garbage bins just in front of their residential building without time limitation and extra fees.

According to studies, however, the program has made limited progress [7], which is also the finding in a survey conducted in October 2012 by the Beijing-based environmental organization Friends of Nature [8].

\subsection{Literature Review}

Identifying means of successfully conducting source separation is an issue widely studied around the world. Researchers have identified a number of collection systems that help achieve a balance between generators that want their waste collected with minimal inconvenience and disposal operators that need to be given waste in a manner compatible with the treatments they employ. For example, Dahlén et al. [9] compared three different collection systems for sorted household waste in Sweden. Gallardo et al. [10,11] analyzed collection systems for sorted household waste in cities and towns in Spain. González-Torre and Adenso-Díaz [12] and Gallardo et al. [10] concluded that distance between containers and citizens was the key to encouraging more people to properly recycle their household waste. Apart from that, Gomes et al. [13] performed economic assessments in Portugal to compare alternative methods of collecting organic waste. Many researchers have also focused on variables that affect selective collection. Bernstad [14] showed that convenient infrastructure for source segregation of kitchen waste is an important factor in household waste recycling in Sweden, and highlighted the need to 
address this aspect where waste is generated, that is, in the household. Shaw and Maynard [15] conducted a UK-based study that summarized the fundamental design variables for recycling schemes such as the number of separations residents must make at home, provision of collection containers, collection frequency, educational programs, and financial incentives. Notably, to identify household waste-sorting preferences, researchers have widely adopted choice experiments (CEs) in which residents were given an opportunity to choose the waste management system's components, such as in Japan by Sakata [16], in London by Karousakis [17], and in Poland by Czajkowski [3].

A number of published papers have investigated recycling of source-separated Chinese household waste. For example, Tai et al. [18] conducted a comparative analysis on eight major cities in China, which launched MSW source-separated collection in 2000. Zhuang et al. [19] proposed a novel source separation method, according to which household waste was classified as food waste, dry waste, and harmful waste in Hangzhou. Yang et al. [20] established a mathematical model of source separation activity, and Deng et al. [7] conducted a survey on the status quo of household waste separation in Beijing and conducted simple statistical analysis. Huang et al. [21] pointed out the importance of not only financial investment for household kitchen waste sorting and reduction but also of appropriate stakeholders in the context of the wider considerations of creating an overall environment for food waste recycling as a mainstream system. Zhou et al. [22] conducted a cost-benefit analysis on a waste-to-market model based on extra bonus for households separating organic wastes in a community with 76 households in Guiyang, southwest China. Yuan and Yabe [23] analyzed Beijing resident's willingness to pay for the household kitchen waste separation services. However, little attention has been paid to resident attitudes, perceptions, and services preferences, especially the preference heterogeneity of the residents on kitchen waste separation services, which is vital for assisting governments in improving the program and formulating more efficient and sustainable source separation services management policies.

Furthermore, although several studies [3,17,24,25] have recognized that household-level separation is inconvenient for the households since it requires space, time, and effort, exactly how they would like to be compensated for their behavior and inconvenience has not been discussed.

\subsection{Purpose and Main Results of This Study}

This study would like to estimate an improved household kitchen waste separation services, employing a stated-preference CE method to shed light on residents' valuation, via households' willingness to accept (WTA) compensation for their source separation behavior of household kitchen waste in the survey area of Beijing City. Moreover, how preference differs between young, middle, and old age groups of respondents and their marginal willingness to accept (MWTA) compensation for the service attributes were also evaluated.

This study is organized as follows: Section 2 presents the theory underlying the CE method. Section 3 discusses the design and data collection of the CE survey, whose results are reported in Section 4. Section 5 concludes with policy implications.

\section{Theoretical Background of the Choice Experiment (CE) Method}

The CE approach is an economic and environmental valuation technique. It uses a simulated market to directly elucidate respondent preferences and WTA for presumably improved service options. It has 
been criticized as, for instance, a means of estimating welfare and deriving value for a sequence of elements implemented by a policy or project, but recently, the application of the CE approach has been extended to various areas owing to its strengths in areas including estimating implicit prices for attributes, welfare impacts for multiple scenarios, and the level of customer demand for alternative "service products" in non-monetary terms, such as tourism [26,27], health care [28,29], wetlands [30], air pollution [31], and many other sites. The CE approach has also been applied in studies related to household waste recycling preferences in many counties [3,16,17,32].

The CE method has its theoretical grounding in Lancaster's model of consumer choice [33] and its econometric basis in random utility theory [34,35]. Lancaster proposed that consumers derive satisfaction not from goods themselves but from the attributes they provide.

Consider a respondent's choice of source separation services. The utility for option $i$ depends on the attributes $(Z)$ of the services and socioeconomic characteristics $(S)$ of the respondent and can be expressed as:

$$
U_{\text {in }}=V_{\text {in }}+\varepsilon_{\text {in }}=V\left(Z_{\text {in }}, S_{n}\right)+\varepsilon_{\text {in }}
$$

The probability that individual $n$ will choose option $i$ over another option $j$ is given as:

$$
P_{i}=P\left(V_{i n}+\varepsilon_{i n}>V_{j n}+\varepsilon_{j n} ; \forall j \in C\right)
$$

where $C$ is the complete choice set. The error terms of the utility function are assumed to be independent and identically distributed (IID) with the property of independence of irrelevant alternatives (IIA). The IIA property states that the probability of choosing an alternative is dependent on the utility of the respective options. The probability of choosing option $i$ is estimated with the multinomial logit (MNL) model, which is as follows:

$$
P_{i}=\frac{\operatorname{Exp}\left(V_{i n}\right)}{\sum_{j \in C} \operatorname{Exp}\left(V_{i n}\right)}
$$

The utility function in linear parameters for the $j$ th alternative is specified as follows:

$$
V_{j n}=\mathrm{ASC}+\beta_{1} X_{1}+\beta_{2} X_{2}+\cdots+\beta_{k} X_{k}+\gamma_{1} S_{1}+\gamma_{2} S_{2}+\cdots+\gamma_{p} S_{p}
$$

where $k$ is the number of attributes and $p$ is the number of socioeconomic variables. The parameters of $\beta$ are often not specified and vary with the alternatives in the choice sets, meaning that the impact of a choice-specific variable on the odds of a given option being chosen is the same without the consideration of alternatives. ASC is an alternative-specific constant. It captures any systematic variations in choice observations that are associated with an alternative and that are not explained by the attribute variation or the observed socioeconomic characteristics of the respondents. There are $j-1$ ASCs in an MNL of $j$ options.

\section{Questionnaire Design}

The first step in a CE design is to define the separation services in terms of its attributes and the levels these attributes take. As mentioned in the literature review, the attributes of distances citizens walk, collection frequency, number of separations, educational programs, and incentives are important for promoting citizens' participation in waste recycling. However, this study only focused on household kitchen waste separation and was based on the current collection system in which bins for kitchen waste are placed in front of individual apartment buildings. This constitutes the shortest distance between 
containers and citizens. Therefore, collection frequency and time, education, and incentives were the most important service attributes and were chosen as the target attributes of this study. Education is presented as instructor which has been included in the current program. To estimate the influence of incentives, non-cash incentive containers and cash incentive compensation were adopted. Their levels are listed in Table 1. The delivery and collection frequency has two levels, namely once per day and twice per week. The two levels of delivery and collection time are evening and morning. The separation instructor also has two levels of need and no need. The two levels for household kitchen waste container are biodegradable plastic bag and barrel. For the bid range of compensation, considering that few studies have conducted kitchen waste separation behavior valuation surveys, we first designed four levels based on the current household waste cleaning fee of Beijing, which is 3 Chinese Yuan Renminbi (CNY) (US\$ 0.48) per household per month, and then tested and adjusted them by the pretested survey. Finally, four levels, that is, $1 \mathrm{CNY}$ (US\$ 0.16), $5 \mathrm{CNY}$ (US\$ 0.81), $8 \mathrm{CNY}$ (US\$ 1.29), and $10 \mathrm{CNY}$ (US\$ 1.62) per household per month, are used.

Table 1. Attributes of household kitchen waste separation services and their levels used in choice experiment (CM) study.

\begin{tabular}{lcc}
\hline Attribute & Levels & Description and Coding of Levels \\
\hline 1. Frequency & 2 & Once per day $v s$. Twice per week \\
2. Time & 2 & Morning $v s$. Evening \\
3. Instructor & 2 & Need $v$ s. No need \\
4. Container & 2 & Plastic bag $v s$. Barrel \\
5. Compensation & 4 & 1 CNY per month per household; 5 CNY per month per household; \\
& & 8 CNY per month per household; 10 CNY per month per household \\
\hline
\end{tabular}

A number of unique, household kitchen waste recycling service specifications can be constructed from these five attributes; four with two levels and one with four levels $\left(2^{4} \times 4=64\right)$. However, it is difficult to use 64 combinations of profiles in the questions. Therefore experimental design techniques [36] were used with the SPSS conjoint software to obtain an orthogonal design consisting of only main effects, which resulted in 16 pair-wise comparisons of alternative collection services. These were randomly blocked into five different versions, four of which presented three choice sets while one had four. Figure 1 provides a sample choice set. Each set contained two collection service profiles (Option A and B), besides an "opt out" alternative (Option C) where neither A nor B is selected, in which case the respondents were told that separation services would not be provided. Such an opt out option can be considered a status quo or baseline alternative, whose inclusion in the choice set is instrumental to achieving welfare measures that are consistent with demand theory [36-38]. Further, respondents were required to choose one out of these three options.

Before the CE question was asked, questions relating to households' knowledge and awareness of the environment and household kitchen waste management in general, as well as their current situation regarding household kitchen waste generation and separation, were covered. These are very essential to reduce potential information bias because of the limitation of respondents' knowledge in terms of source separation. At the end of the questionnaire, socioeconomic information on the respondents was collected. 
To ensure the quantity and quality of kitchen waste sent into the compost system and high levels public participation, here the compost company would like to change the current service values and provide relevant compensation for these changes. Some detailed service attributes are listed as follows. Please compare the choice sets carefully and then choose one $(\sqrt{ })$ :

\begin{tabular}{|c|c|c|c|}
\hline Attributes & Option A & Option B & Option C \\
\hline Frequency & 2/week & $1 / d a y$ & \multirow{5}{*}{$\begin{array}{l}\text { Neither service A nor B: I do } \\
\text { not wish to participate in this } \\
\text { kitchen waste separation } \\
\text { program. }\end{array}$} \\
\hline Time & Evening & Morning & \\
\hline Instructor & Need & No need & \\
\hline Container & Barrel & Plastic bag & \\
\hline $\begin{array}{l}\text { Compensation (CNY per household per } \\
\text { month) }\end{array}$ & 10 & 1 & \\
\hline Which option do you prefer?(tick only one) & & & \\
\hline
\end{tabular}

Figure 1. Example of a household kitchen waste separation services choice set.

\section{Data collection}

So far, most of the successful cases of economic incentive approaches on household waste recycling are in developed countries such as Netherlands, Belgium, Italy, Luxemburg, Sweden, and especially Denmark and Ireland $[39,40]$. Thus, we suppose the reason for this is that high- educated and income residents are more prone to support waste sorting than others. Thus, in order to know how behavior change is related to economic persuasion in China, we have to observe several model areas for checking individual recycling activities. As we all know, Beijing is one of the international big cities of China, and has a high percentage of highly-educated and high-income people, especially in the center area. Therefore, this study focused on the center (Beijing proper and urban) area of Beijing City which includes six districts (Figure 2): Dongcheng, Xicheng, Haidian, Chaoyang, Fengtai, and Shijingshan. During this survey, a three-stage sampling technique was employed. The first stage involved the use of purposive sampling techniques whereby two districts-Haidian and Dongcheng-were selected. Because of time and budget constraints, 12 communities ( 8 from Haidian and 4 from Dongcheng) were randomly selected from all of the 651 pilot communities of Dongcheng and Haidian districts (511 from Haidian and 140 from Dongcheng). During the third stage, respondents were collected in convenience samples and interviewed face-to-face in each selected community. It was realized that, each target community has different number of residential buildings with different number of households. In order to get these information and make sure the selected households cover all parts of the area, we visited the community service center of each target community before conducting survey. Besides, to avoid interviewing only a particular group of respondents such as the unemployed, seniors or retirees, the interviewers visited the communities at different times of the day.

The survey took place from 20 June to 1 August 2013. The pretested survey conducted in the first 7 days involved 30 households in three pilot communities not only to test the bid range for the monetary attribute required to estimate the value of the kitchen waste separation services attributes, as mentioned before, but also to ensure that the questionnaire was easy to understand. Finally, five versions of the questionnaire were equally likely to be presented to a given household. At the end of the survey, we approached 401 households and managed to complete 394 interviews for a $98.3 \%$ response rate. 


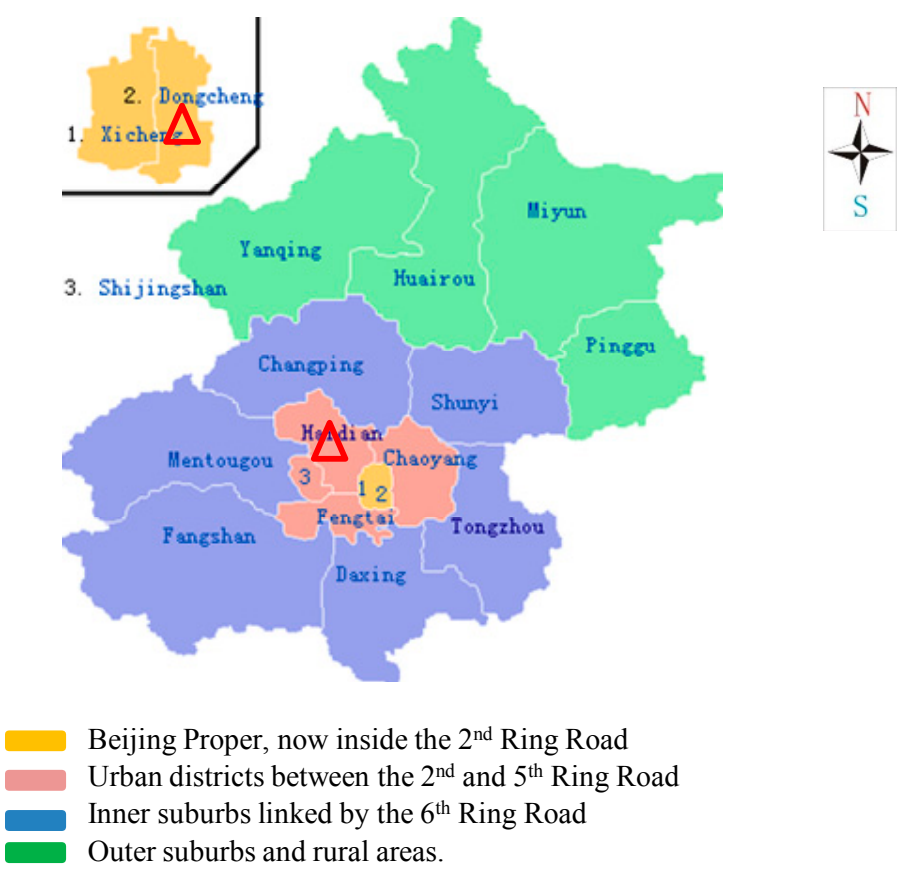

Figure 2. Beijing map and survey area (Source: Google map).

\section{Results}

Table 2 gives descriptive statistics of the main socioeconomic characteristics of the respondents and statistical results from the Beijing Statistic Yearbook [41]. The gender distribution in the samples was about 58\% female; higher than the average level. This high percentage may be because the survey was mainly conducted in the daytime, making it more difficult to interview working male respondents. About $57.4 \%$ respondents were between 30 to 59 years old. The highest percentage of respondents had attained a four-year university degree or higher level of education (approximate $42 \%$ ). This is higher than the average Beijing statistical level of $\sim 32 \%$, but is reasonable because central urban areas typically have more highly educated residents than suburban areas. Almost $61 \%$ were local people, and the highest percentage of households had three residents. About $70 \%$ were living in their own apartment. To estimate respondents' satisfaction with their household income, we asked them to assess their household's economic level among urban Beijing households as being low, medium, or high. Less than $33 \%$ of the respondents reported their economic level as low. About $12.4 \%$ of the respondents had or once had an environmental member in their family, and, according to their self-estimation, no more than $30 \%$ always or most times separated their kitchen waste at source. Of the sampled households, 265 were from the Haidian district and 129 from the Dongcheng district. The bias of sample distribution to the statistics in Haidian and Dongcheng districts is probably because the target communities were randomly selected from all pilot communities in the two districts, as mentioned in the section on data collection. The irreconcilable sample distribution is therefore possibly understandable. The numbers of respondents for the five versions of the questionnaire were $79,79,79,80$, and 77, respectively. 
Table 2. Socioeconomic characteristics of the sample and statistics.

\begin{tabular}{|c|c|c|c|c|}
\hline Category & Levels & Frequency & $\%$ & $\%^{s}$ \\
\hline \multirow{2}{*}{ Gender } & Male & 166 & 42.1 & 50 \\
\hline & Female & 228 & 57.9 & 50 \\
\hline \multirow{3}{*}{ Age (in years) } & $\geqslant 29$ & 66 & 16.7 & 38 \\
\hline & $30 \sim 59$ & 226 & 57.4 & 48 \\
\hline & $\leqslant 60$ & 102 & 25.8 & 14 \\
\hline \multirow{2}{*}{ Local } & Yes & 240 & 60.9 & 63 \\
\hline & Otherwise & 154 & 39.1 & 37 \\
\hline \multirow{5}{*}{$\begin{array}{l}\text { Household size (in } \\
\text { person) }\end{array}$} & 1 & 26 & 6.6 & 22 \\
\hline & 2 & 70 & 17.8 & 31 \\
\hline & 3 & 136 & 34.5 & 31 \\
\hline & 4 & 76 & 19.3 & 9 \\
\hline & $\leqslant 5$ & 86 & 21.8 & 7 \\
\hline \multirow{2}{*}{ House ownership } & Own house & 277 & 70.3 & \multirow{2}{*}{--} \\
\hline & Otherwise & 117 & 29.7 & \\
\hline \multirow{2}{*}{$\begin{array}{c}\text { Environmental } \\
\text { member }\end{array}$} & Yes or once & 49 & 12.4 & \multirow{2}{*}{--} \\
\hline & Otherwise & 345 & 87.6 & \\
\hline \multirow{3}{*}{ Economical level } & Low & 128 & 32.5 & \multirow{3}{*}{--} \\
\hline & Middle & 195 & 49.5 & \\
\hline & High & 71 & 18 & \\
\hline \multirow{3}{*}{ Education } & No high school & 125 & 31.7 & 44 \\
\hline & High school or equivalent & 103 & 26.1 & 22 \\
\hline & College or above & 166 & 42.1 & 32 \\
\hline \multirow{2}{*}{ Separation } & Always or most times & 115 & 29.2 & \multirow{2}{*}{-- } \\
\hline & Otherwise & 279 & 70.8 & \\
\hline \multirow{2}{*}{ District } & Haidian & 265 & 67.3 & 79 \\
\hline & Dongcheng & 129 & 32.7 & 21 \\
\hline \multirow{5}{*}{ Version } & 1 & 79 & 20.1 & \multirow{5}{*}{--} \\
\hline & 2 & 79 & 20.1 & \\
\hline & 3 & 79 & 20.1 & \\
\hline & 4 & 80 & 20.3 & \\
\hline & 5 & 77 & 19.5 & \\
\hline Total & -- & 394 & 100 & 100 \\
\hline
\end{tabular}

Because the Yearbook is limited in that it does not provide exact attribute distribution of the centre urban areas of Beijing. Therefore, the values from the Yearbook results cannot be seen as a precise reference for the survey. However, the Table 2 also shows that the number of people in households in our sample was significantly different to those typically in Beijing, and since this factor is a significant influence on waste produced and recycling rates, we note that although our study might provide some policy suggestions, they would need further investigation.

Besides, we asked the respondents to roughly estimate how many kilograms of kitchen waste each household produced on average per day during the last week (Figure 3). This could help them assess 
their daily quantity of kitchen waste and the need to take part in its recycling. Approximately $30 \%$ of the respondents reported $1 \mathrm{~kg}$, followed by $0.5 \mathrm{~kg}$ (about 23\%) and $1.5 \mathrm{~kg}(18 \%)$.

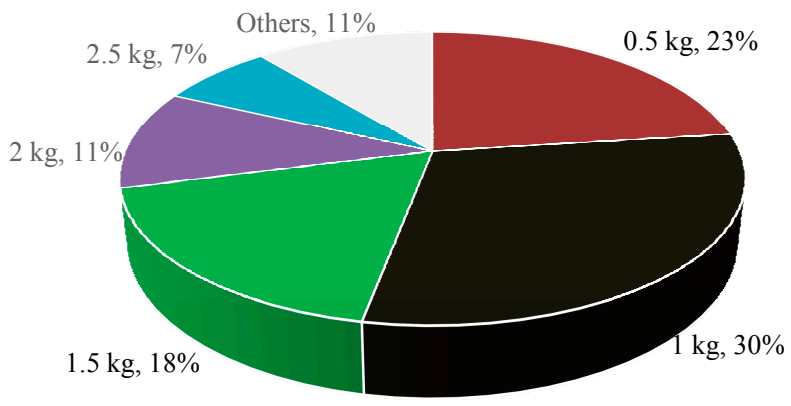

Figure 3. Distribution of the quantity of household kitchen waste on average per day during the last week $(n=394)$.

\subsection{Results of Multinomial Logit Model}

Assuming IID error terms with an extreme value type 1 Gumbel distribution, an MNL model can be used to estimate the attribute coefficients. In the choice model analysis, the utility functions depicted in Equation (4) are econometrically estimated using an MNL regression with the software package LIMDEP 8.0 NLOGIT 4.0 [42]. The variables and their coding for the model are presented in Table 3.

Table 3. Variables included in multinomial logit model analysis and their levels.

\begin{tabular}{|c|c|}
\hline Variables & Definition \\
\hline \multicolumn{2}{|r|}{ Attribute Variables } \\
\hline ASC & $\begin{array}{l}\text { Alternative-specific constant (e.g., } \mathrm{ASC}=1 \text { if the individual chose Option A or B, } \\
\text { and } \mathrm{ASC}=0 \text { if the individual chose Option C) }\end{array}$ \\
\hline Frequency & $1=$ Once per day; $0=$ Twice per week \\
\hline Time & $1=$ Morning; $0=$ Evening \\
\hline Instructor & $1=$ Need; $0=$ No need \\
\hline Container & $1=$ Plastic bag; $0=$ Barrel \\
\hline Compensation & $\begin{array}{l}1 \mathrm{CNY} \text { per month per household; } 5 \mathrm{CNY} \text { per month per household; } \\
8 \mathrm{CNY} \text { per month per household; } 10 \mathrm{CNY} \text { per month per household }\end{array}$ \\
\hline \multicolumn{2}{|r|}{ Non-attribute Variables } \\
\hline Gender & $1=$ Male $; 0=$ Female \\
\hline Education & $1=$ College or above; $0=$ otherwise \\
\hline Elev1 & Economic level: $1=$ low; $0=$ otherwise \\
\hline Elev2 & Economic level: $1=$ middle; $0=$ otherwise \\
\hline Local & $1=$ local; $0=$ otherwise \\
\hline Separation & Frequency of kitchen waste separation: $1=$ always or most times; $0=$ otherwise \\
\hline
\end{tabular}

Table 4 shows the regression results with all respondents, and with respondents grouped by age group, that is, young (less than 30 years old), middle (30-59 years old) and old (over 59 years old) age. There are two types of models. First, the basic specification models (M1, M3, M5, and M7) show the importance of the attributes in the respondents' choice from among the three different options. Models of the second type (M2, M4, M6, and M8) include attribute variables and interaction variables generated 
from the interaction of seven socioeconomic characteristic with an alternative-specific constant that could improve model fit and remove IIA and IID violations [43]. Besides, the inclusion of these socioeconomic variables also helps to capture the heterogeneity in preferences and estimate the effects of attribute changes on the probability that the improved or base option will be chosen. With the inclusion of the socioeconomic terms, the model fit improves as measured by higher $\rho^{2}$. The Swait-Louviere

log-likelihood ratio test rejects the null hypothesis that the regression parameters for these two types of models are equal at the $5 \%$ significance level. Thus, the models with socioeconomic variables are better than those with only attributes and will be used for the final interpretations of the CE model.

Table 4. Multinomial logit model estimates for all respondents, and respondents grouped by age group.

\begin{tabular}{|c|c|c|c|c|c|c|c|c|}
\hline \multirow{2}{*}{ Attribute } & \multicolumn{2}{|c|}{ All Respondents } & \multicolumn{2}{|c|}{ Age Less than 30} & \multicolumn{2}{|c|}{ Age 30-59 } & \multicolumn{2}{|c|}{ Age over 59} \\
\hline & M1 & M2 & M3 & M4 & M5 & M6 & M7 & M8 \\
\hline ASC & $-0.422^{* * *}$ & $-0.831^{* * *}$ & -0.159 & 0.319 & -0.266 & $-0.987^{* * *}$ & $-1.036^{* * *}$ & $-1.324^{* * *}$ \\
\hline Frequency & $1.135^{* * *}$ & $1.173^{* * *}$ & $0.734^{* * * *}$ & $0.749^{* * *}$ & $1.123^{* * * *}$ & $1.156^{* * * *}$ & $1.476^{* * * *}$ & $1.573^{* * *}$ \\
\hline Time & $-0.218^{* *}$ & $-0.223^{* *}$ & -0.317 & -0.296 & $-0.198^{*}$ & $-0.201^{*}$ & -0.196 & -0.192 \\
\hline Instructor & -0.112 & -0.109 & 0.112 & 0.169 & -0.022 & -0.048 & $-0.527^{* * *}$ & $-0.482^{* *}$ \\
\hline Container & $0.224^{* *}$ & $0.229^{* *}$ & -0.128 & -0.194 & $0.229^{* *}$ & $0.254^{* *}$ & $0.503^{* * *}$ & $0.465^{* *}$ \\
\hline Compensation & 0.008 & 0.007 & 0.025 & 0.026 & -0.014 & -0.016 & $0.054^{*}$ & 0.050 * \\
\hline ASC $\cdot$ Gender & & -0.005 & & -0.224 & & -0.074 & & 0.338 \\
\hline ASC $\cdot$ Education & & $0.483^{* * *}$ & & $0.639^{*}$ & & $0.470^{* *}$ & & 0.287 \\
\hline ASC·Elev 1 & & $0.489^{* *}$ & & -0.098 & & $0.727^{* *}$ & & 0.308 \\
\hline ASC $\cdot$ Elev 2 & & 0.273 & & -0.387 & & $0.406^{*}$ & & 0.222 \\
\hline ASC·Local & & $-0.709^{* * *}$ & & $-1.366^{* * *}$ & & $-0.378^{* *}$ & & $-1.047^{* *}$ \\
\hline ASC $\cdot$ Separation & & $1.481^{* * *}$ & & 0.680 & & $1.379^{* * *}$ & & $2.240^{* * *}$ \\
\hline Log likelihood & -1289.46 & -1237.31 & -220.43 & -212.62 & -743.19 & -716.88 & -313.13 & -286.12 \\
\hline RsqAdj & 0.06 & 0.09 & 0.02 & 0.04 & 0.06 & 0.09 & 0.1 & 0.17 \\
\hline Iterations completed & 5 & 5 & 4 & 5 & 5 & 5 & 5 & 5 \\
\hline Number of respondents & 394 & 394 & 66 & 66 & 226 & 226 & 102 & 102 \\
\hline Number of choice sets & 1259 & 1259 & 209 & 209 & 727 & 727 & 323 & 323 \\
\hline
\end{tabular}

* Significant at the $10 \%$ level; ${ }^{* *}$ significant at the $5 \%$ level; ${ }^{* * *}$ significant at the $1 \%$ level.

Table 4 also presents the coefficients for each of the variables in the eight models. Notice that ASC is negative and significant at the 1\% level in M2 with all samples, which means the respondents, on average, prefer the status quo over the proposed separation program. Furthermore, they prefer services with frequent, evening, and plastic bag attributes. Moreover, respondents in different age groups respond differently to the attributes in the choice sets. Young respondents in M4 care only about the collection frequency, middle-age respondents in M6 prefer services with collection frequency, evening collection, and free plastic bag attributes, while elder people as M8 shows prefer services with frequent collection, no instructor, free plastic bag, and compensation attributes. In detail, for the five attributes of the choice sets, frequency has a positive coefficient at the $1 \%$ level among the three age groups in which respondents prefer kitchen waste services with greater collection frequency. The time attribute was not a significant incentive for either the young or the old age group, while for the middle age group, it was 
negatively significant at the 5\% level, which means they are prone to deliver kitchen waste in the evening time and prefer evening collection to morning. The insignificant instructor parameter in the young and middle age groups and the negative, significant coefficient in the old age group indicate that the availability of an instructor is not a major incentive for the surveyed residents to accept separation services. The container attribute has little impact on the young respondents' choice making, while it has a significant and positive effect on middle- and old-age choice behavior. Another important difference between the age groups is that the compensation attribute is not significant in the young and middle age groups, which indicates that low compensation is not a major factor in inducing their preference for the proposed kitchen waste source separation program. On the contrary, it is significant at the $10 \%$ level in the last age group.

Concerning the socioeconomic parameters, non-local citizens in the young age group with university or higher degrees are willing to accept source separation services, middle-aged lower-income respondents with university or higher degrees and non-local citizens are more likely to accept these services, and non-local citizens in the old age group prefer kitchen waste collection services. Regarding the separation experience, respondents whose families conduct kitchen waste separation are more likely to support the proposed source separation program.

\subsection{Marginal Willingness to Accept Estimates}

From Table 4, we can estimate the MWTA compensation of the old age group for significant variables. The MWTA compensation can be estimated from the marginal rate of substitution between the coefficients of the attribute and the monetary variable as follows:

$$
\text { MWTA Compensation }=-\frac{\beta_{\text {attribute }}}{\beta_{\text {compensation }}}
$$

Table 5 shows the MWTA compensation results. The estimates are based on the important attributes of the above-60-year-old age group. The results show the MWTA compensation of elder residents for the frequency attribute is about $-31.3 \mathrm{CNY}$ (US\$ -5.05) per household per month with a $95 \%$ confidence interval (CI) between -67.5 CNY (US\$ - 10.90) and 4.9 CNY (US\$ 0.79). This means when the frequency attribute changes from twice per week to once per day, the elder group respondent's MWTA compensation becomes negative, in other words, their marginal willingness to pay is US\$5.05.

Table 5. Marginal willingness to accept (MWTA) compensation estimates for age group above 60 in Chinese Yuan Renminbi (CNY).

\begin{tabular}{cccc}
\hline Attribute & Value & M7 & M8 \\
\hline \multirow{2}{*}{ Frequency } & Coefficient & $-27.4^{*}$ & $-31.3^{*}$ \\
& $95 \% \mathrm{CI}$ & $(-56.1,1.3)$ & $(-67.5,4.9)$ \\
\multirow{2}{*}{ Instructor } & Coefficient & 9.8 & 9.6 \\
& $95 \% \mathrm{CI}$ & $(-2.6,22.2)$ & $(-3.9,23.1)$ \\
\multirow{2}{*}{ Container } & Coefficient & $-9.3^{*}$ & -9.3 \\
& $95 \% \mathrm{CI}$ & $(-19.8,1.2)$ & $(-20.9,2.4)$ \\
\hline
\end{tabular}

* Significant at the $10 \%$ level; the $95 \%$ confidence interval (CI) was estimated following the procedure suggested by Hanemann and Kanninen [44]; MTWA = marginal willingness to accept. 


\section{Discussion}

The results of our analysis suggest a potential for improvement in the source separation services program in Beijing. Unlike Czajkowski et al. [3], the results of frequency variable are comparable to Karousakis and Birol [17]. Respondents were more willing to accept services with frequent collection. As regards collection time, this study explores the possibility of evening collection-encouraging households to take out their separated kitchen waste in the evening and deposit it correctly into the community kitchen waste bin, from where it is taken to the disposing site by the collection vehicle. The findings for all age groups showed little or negative interest in the kitchen waste separation instructor. It might thus be worthwhile for the local government to reconsider instructor investment. With regard to the non-cash incentive container factor, the government could consider providing free environment-friendly plastic bags as a long-term incentive. The findings also showed that only old respondents show positive and significant preference for compensation. It would take a great amount of money to install infrastructure (e.g., human resources, garbage bins, transportation facilities, final disposal equipment) in all communities in urban Beijing. Governments could start the program from communities that have a high percentage of older residents and compensate households that separate kitchen waste correctly, which could encourage more separation at the source. By this means, governments can save on costs of achieving separation goals before popularizing the separation campaign in the Beijing area.

\section{Conclusions}

This paper analyzes the preferences of young, middle, and elder age group residents to engage in an improved source separation services program, their socioeconomic determinants, and their MWTA compensation for specific service attributes, namely, delivery frequency, household kitchen waste container, and availability of instructor in Haidian and Dongcheng districts of Beijing City. A CE method was applied to determine the preferences of residents and their MWTA compensation. MNL models were used to analyze resident preferences by age group.

The results show there are differences of preferences on the services attributes between young, middle, and old age respondents. Low compensation is not a major factor to promote young and middle age residents accept the proposed separation services. However, on average, most of them prefer services with frequent, evening, plastic bag attributes and without instructor. The results from this study, however, cannot be generalizable because of the non-typical nature of the sample of residents used. In other words, the results may not be applicable to the entire Beijing area but they may be useful for suggestions to be investigated further for potential policy implications and may serve as a leeway to the next steps in reach in the area regarding WTP for better kitchen waste separation services.

A potential area for further research in the field of household kitchen waste separation could be investigations of residents from more typical households, especially taking household size (number of people in the household) into account. Besides, the low compensation levels set in this study presented some limitations to the MWTA estimations for young and middle-aged respondents considering that this is an exploratory study in the area of waste separation to detect residents' WTA compensation by the CE 
method and the unavoidable sampling bias of the pretest survey for compensation attribute levels. Therefore, the compensation levels should be increased in future studies.

\section{Acknowledgments}

The authors are grateful to the three anonymous referees and the Editors for their constructive criticism and insightful suggestions. The authors would like to acknowledge the advice, comments, and suggestions from postdoctoral fellow Huynh Viet Khai and members of the Laboratory of Environmental Economics, Kyushu University, Japan. Yalin Yuan is sponsored by the China Scholarship Council under Grant No. 2011630098. This work was supported by JSPS KAKENHI Grant Number 26310311.

\section{Author Contributions}

Yalin Yuan and Mitsuyasu Yabe conceived and designed the questionnaire; Yalin Yuan conducted the survey; Yalin Yuan and Mitsuyasu Yabe analyzed the data; Yalin Yuan wrote the paper; Mitsuyasu Yabe edited the paper.

\section{Conflicts of Interest}

The authors declare no conflict of interest.

\section{References}

1. Suttibak, S.; Nitivattananon, V. Assessment of factors influencing the performance of solid waste recycling programs. Resour. Conserv. Recycl. 2008, 53, 45-56.

2. Tadesse, T. Environmental concern and its implication to household waste separation and disposal: Evidence from Mekelle, Ethiopia. Resour. Conserv. Recycl. 2009, 53, 183-191.

3. Czajkowski, M.; Kądziela, T.; Hanley, N. We want to sort! Assessing households' preferences for sorting waste. Resour. Energy Econ. 2014, 36, 290-306.

4. Eugenia, C.B.; Georgina, N.; Ramil, L. Solid waste segregation and recycling in Metro Manila: Household attitudes and behaviour; Resource, Environment and Economic Centre for Studies: Quezon City, Philippines, 2002.

5. Li, Z.; Yang, L.; Qu, X.; Sui, Y. Municipal solid waste management in Beijing City. Waste Manag. 2009, 29, 2596-2599.

6. Beijing Municipal Bureau of Statistics. Beijing Statistical Yearbook; Beijing Statistics Press: Beijing, China, 2010.

7. Deng, J.; Xu, W.; Zhou, C. Investigation of waste classification and collection actual effect and the study of long acting management in the community of Beijing. Environ. Sci. 2013, 1, 395-400.

8. A Research Report on Garbage Separation of Pilot Communities in Beijing in 2012. Available online: http://www.fon.org.cn/uploads/attachment/17641370277681.pdf (accessed on 30 April 2013).

9. Dahlén, L.; Vukicevic, S.; Meijer, J.-E.; Lagerkvist, A. Comparison of different collection systems for sorted household waste in sweden. Waste Manag. 2007, 27, 1298-1305. 
10. Gallardo, A.; Bovea, M.D.; Colomer, F.J.; Prades, M.; Carlos, M. Comparison of different collection systems for sorted household waste in spain. Waste Manag. 2010, 30, 2430-2439.

11. Gallardo, A.; Bovea, M.D.; Colomer, F.J.; Prades, M. Analysis of collection systems for sorted household waste in spain. Waste Manag. 2012, 32, 1623-1633.

12. González-Torre, P.L.; Adenso-Díaz, B. Influence of distance on the motivation and frequency of household recycling. Waste Manag. 2005, 25, 15-23.

13. Gomes, A.; Matos, M.; Carvalho, I. Separate collection of the biodegradable fraction of MSW: An economic assessment. Waste Manag. 2008, 28, 1711-1719.

14. Bernstad, A. Household food waste separation behavior and the importance of convenience. Waste Manag. 2014, 34, 1317-1323.

15. Shaw, P.; Maynard, S. The potential of financial incentives to enhance householders' kerbside recycling behaviour. Waste Manag. 2008, 28, 1732-1741.

16. Sakata, Y. A choice experiment of the residential preference of waste management services-The example of Kagoshima City, Japan. Waste Manag. 2007, 27, 639-644.

17. Karousakis, K.; Birol, E. Investigating household preferences for kerbside recycling services in London: A choice experiment approach. J. Environ. Manag. 2008, 88, 1099-1108.

18. Tai, J.; Zhang, W.; Che, Y.; Feng, D. Municipal solid waste source-separated collection in China: A comparative analysis. Waste Manag. 2011, 31, 1673-1682.

19. Zhuang, Y.; Wu, S.; Wang, Y.; Wu, W.; Chen, Y. Source separation of household waste: A case study in China. Waste Manag. 2008, 28, 2022-2030.

20. Yang, L.; Li, Z.; Fu, H. Model of municipal solid waste source separation activity: A case study of Beijing. J. Air Waste Manag. Assoc. 2011, 61, 157-163.

21. Huang, W.; Wang, J.; Dai, X.; Li, M.; Harder, M.K. More than financial investment is needed: Food waste recycling pilots in Shanghai, China. J. Clean. Prod.2014, 67, 107-116.

22. Community Based Waste-to-Market Model for Sustainable Municipal Solid Waste Management: Closing the Ecological Loop. Available online: http://www.athens2014.biowaste.gr/pdf/zhou_ et_al.pdf (accessed on 12 June 2014).

23. Yuan, Y.; Yabe, M. Residents' willingness to pay for household kitchen waste separation services in Haidian and Dongcheng districts, Beijing city. Environments 2014, 1, 190-207.

24. Victor, O.; Emmanuel, A.; Cecilia, S. Do economic incentives affect attitudes to solid waste source separation? Evidence from Ghana. Resour. Conserv. Recycl. 2013, 78, 115-123.

25. Laurent, A.; Bakas, I.; Clavreul, J.; Bernstad, A.; Niero, M.; Gentil, E.; Hauschild, M.Z.; Christensen, T.H. Review of LCA studies of solid waste management systems-Part I: Lessons learned and perspectives. Waste Manag. 2013, 34, 573-588.

26. Siderelis, C.; Brothers, G.; Rea, P. A boating choice model for the valuation of lake access. J. Leis. Res. 1995, 27, 264-282.

27. Dellaert, B.; Borgers, A.; Timmermans, H. A day in the City: Using conjoint choice experiments to model urban tourists' choice of activity packages. Tour. Manag.1995, 16, 347-353.

28. Gerard, K.; Shanahan, M.; Louviere, J. Using stated preference discrete choice modelling to inform health care decision-making: A pilot study of breast screening participation. Appl. Econ. 2003, 35, $1073-1085$. 
29. Rosko, M.D.; McKenna, W. Modeling consumer choices of health plans: A comparison of two techniques. Soc.Sci. Med. 1983, 17, 421-429.

30. Othman, J.; Bennett, J.; Blamey, R. Environmental values and resource management options: A choice modelling experience in Malaysia. Environ. Dev. Econ. 2004, 9, 803-824.

31. Yoo, S.; Kwak, S.; Lee, J. Using a choice experiment to measure the environmental costs of air pollution impacts in Seoul. J. Environ. Manag. 2008, 86, 308-318.

32. Pek, C.; Jamal, O. A choice experiment analysis for solid waste disposal option: A case study in Malaysia. J. Environ. Manag. 2011, 92, 2993-3001.

33. Lancaster, K.J. A new approach to consumer theory. J. Polit. Econ. 1966, 74, 132-157.

34. Luce, R. Individual Choice Behavior: A Theoretical Analysis; John Wiley and Sons: New York, NY, USA, 1959.

35. Mcfadden, D. Conditional Logit Analysis of Qualitative Choice Behavior; Zarembka, P., Eds.; Frontiers in Econometrics, Academic Press: New York, USA, 1974; pp. 105-142.

36. Louviere, J.J.; Hensher, D.A.; Swait, J.D. Stated Choice Methods: Analysis and Applications; Cambridge University Press: England, UK, 2000; pp. 1-30.

37. Bennett, J.; Blamey, R. The Choice Modelling Approach to Environmental Valuation; Edward Elgar Press: Cheltenham, UK, 2001.

38. Bateman, I.; Carson, R.; Day, B.; Hanemann, W.; Hanley, N.; Hett, T.; Jones-Lee, M.; Loomes, G.; Mourato, S.; Ozdemiroglu, E. Guidelines for the Use of Stated Preference Techniques for the Valuation of Preferences for Non-Market Goods; Edward Elgar Press: Cheltenham, UK, 2003.

39. Jacobsen, H.; Kristoffersen, M.; Tsotsos, D. Case Studies on Waste Minimisation Practices in Europe; European Environment Agency:Copenhagen, Denmark, 2002.

40. Husaini, I.; Garg, A.; Kim, K.-H.; Marchant, J.; Pollard, S.J.; Smith, R. European household waste management schemes: Their effectiveness and applicability in england. Resour. Conserv. Recycl. 2007, 51, 248-263.

41. Beijing Municipal Bureau of Statistics. Beijing Statistical Yearbook; Beijing Statistics Press: Beijing, China, 2013.

42. Hensher, D.A.; Rose, J.M.; Greene, W.H. Applied Choice Analysis: A Primer; Cambridge University Press: England, UK, 2005.

43. Rolfe, J.; Bennett, J.; Louviere, J. Choice modelling and its potential application to tropical rainforest preservation. Ecol. Econ. 2000, 35, 289-302.

44. Hanemann, W.M.; Kanninen, B. The statistical analysis of discrete-response CV data. In Valuing Environmental Preferences: Theory and Practice of the Contingent Valuation Method in the USA, EC, and Developing Countries; Bateman, I.J., Willis, K.G., Eds.; Oxford University Press: New York, NY, USA, 1999; pp. 302-441.

(C) 2014 by the authors; licensee MDPI, Basel, Switzerland. This article is an open access article distributed under the terms and conditions of the Creative Commons Attribution license (http://creativecommons.org/licenses/by/4.0/). 